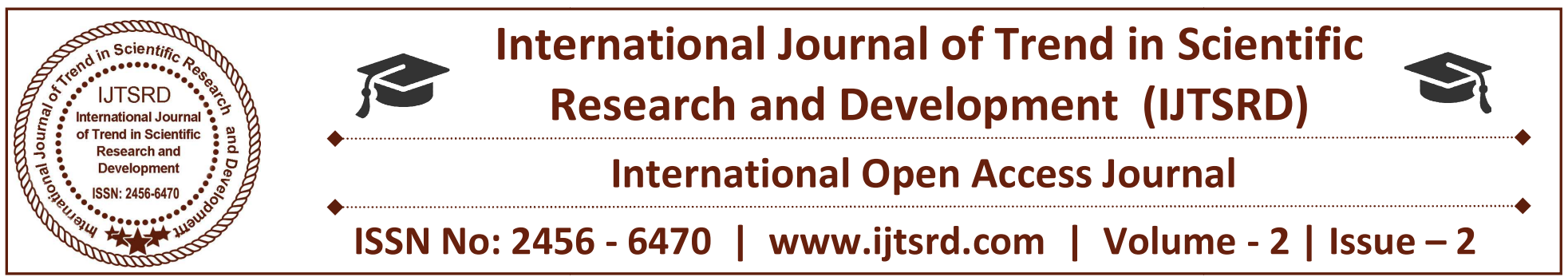

\title{
Warning Signs of Pregnancy among Antenatal Mothers
}

\author{
Ms. Kanchan Bala \\ PhD Scholar, Himalayan \\ University, Itanagar, Arunachal \\ Pradesh, India
}

\author{
Dr. Balwinder Kaur Buttar \\ NRI College of Nursing, \\ Amritsar, Punjab, India
}

\author{
Dr. Ramesh Singh \\ Principal, Mai Bhago College of \\ Nursing, Taran Taran, \\ Punjab, India
}

\begin{abstract}
"Maternal health is Nation's wealth. There is a chance for the welfare of the world only when the condition of the women improves. It is not possible for a bird to fly on only one wing." The aim of the present study was to find the level of knowledge regarding warning signs of pregnancy among antenatal mothers. A cross sectional survey design was used. Convenient sampling technique was used to select 50 antenatal mothers from selected community area of Doiwala, Dehradun, Uttarakhand. Data was collected by using structured knowledge questionnaire regarding selected warning signs of pregnancy. Result showed that the overall mean knowledge score was $(14 \pm 2.46)$ and mean percentage was $56 \%$. Knowledge score of antenatal mothers ranges from 7- 18 (maximum 25). Mothers gained maximum mean score $(2.72 \pm 0.83)$ in the area of decrease fetal movement and the lowest mean score $(1.14 \pm 0.40)$ in the area of per vaginal discharge. No significant association was found between level of knowledge score with their demographic variables except type of family.
\end{abstract}

Keywords: Warning signs, Pregnancy, Knowledge, Antenatal mothers

\section{Introduction}

Every pregnant woman faces the risk of sudden, unpredictable complications that could end in death or injury to herself or to her infant. Pregnancy related complications cannot be reliably predicted, hence, it is necessary to employ strategies to overcome such problems Every pregnant woman faces the risk of sudden, unpredictable complications that could end in death or injury to herself or to her infant. Pregnancy related complications cannot be reliably predicted, hence, it is necessary to employ strategies to overcome such problems as they arise. Maternal mortality and morbidity are complex problems that require interventions.

Improving maternal mortality has received recognition at a global level as evidenced by the inclusion of reducing maternal mortality in the Millennium Development Goals. It is difficult to predict that which women will experience life threatening obstetric complications which can lead to maternal mortality, receiving care from a skilled provider (doctor, nurse or midwife) during the process of childbirth has been identified as the single most important intervention in safe motherhood. ${ }^{2}$

Pregnancy starts with conception, and ends with delivery of the baby. Preparing for childbirth is one of the most exciting time for a woman; however, it may also create fear and anxiety for a mom-to-be. During this transitional period, woman may start preparing for the special new addition to her family, she may also have to come to terms with the many adjustments that will have to be made. Staying organized, positive, relaxed and planning properly can help make the childbirth process easier. ${ }^{3}$

Motherhood is a great responsibility and it is woman's highest crown of honour. The word "pregnant" comes from Latin word 'pre' meaning before, '(g)natus' meaning birth, so the pregnant means before (giving) birth. ${ }^{4}$ Pregnancy is the vital event in the life of a 
woman. It needs special attention from the time of conception to the postnatal stage. Antenatal care services are important for ensuring the reproductive health of the mothers and for the better outcome of pregnancy. ${ }^{5}$

In India, most of the mothers have poor knowledge regarding antenatal, intranatal care and postnatal care. ${ }^{6}$ Every day, approximately 800 women die from preventable causes related to pregnancy and childbirth. Ninety Nine percent of all maternal deaths occur in developing nations. Maternal mortality is higher in women living in rural areas and among poorer communities. Young adolescents face a higher risk of complications and death as a result of pregnancy than older women. Rendering skilled care throughout childbirth can save the lives of women and newborn babies. Between 1990 and 2013, maternal mortality worldwide dropped by almost $50 \%{ }^{7}$

High risk pregnancy is a critical problem for modern medical and nursing care. The leading cause of maternal attributable to pregnancy differs over the world the factors that are strongly related to maternal death include age, lack of prenatal care, low educational attainment. ${ }^{8}$

Present study focused to find the knowledge of antenatal mothers regarding warning signs of Pregnancy.

\section{Methodology}

Research design used for the study was cross sectional. The study was conducted in community area of Doiwala block, Dehradun, Uttarakhand. 50 antenatal mothers were selected by convenient technique who fulfilled the selection criteria. Data was collected with the help of structured knowledge questionnaire consisting of- Section A (Sociodemographic variables such as age, religion, area of living, mother education, mother occupation, income, no. ANC visits.

Section B (consisting of 25 items related to Knowledge regarding warning signs) The content validity of the tool was ensured by giving the tool to experts in the field of nursing and Medical. Reliability of tool was established by split half method following spearman brown formula. The reliability of tool was calculated and it was $r=0.93$.

\section{RESULT}

The results are organized according to the objectives of the study.

\section{Sample characteristics}

Most of the mothers (46\%) were at the age of 26- 30 years and $(58 \%)$ were belongs to nuclear family. All mothers $(100 \%)$ were Hindu. Majority of mothers (96\%) was living in urban area, (44\%) mothers were having secondary education and (58\%) mothers were multigravida. All the mothers $(100 \%)$ were homemaker and majority of mothers $(66 \%)$ have visited ANC OPD for 3-5 time, (94\%) mothers were not having any history of abortion.

\section{Level of knowledge of mothers regarding warning signs of pregnancy}

Table No-1 Level of knowledge of mothers regarding warning signs of pregnancy $\mathbf{N}=\mathbf{5 0}$

\begin{tabular}{|l|l|l|l|}
\hline \multirow{2}{*}{ Knowledge Score } & $\begin{array}{l}\text { Range } \\
\text { Score }\end{array}$ & Mean \pm SD & Mean percentage \\
\cline { 2 - 4 } & $7-18$ & $14 \pm 2.46$ & $56 \%$ \\
\hline
\end{tabular}

Table no-1 shows that the range of knowledge score of mothers regarding warning signs of pregnancy was 718 and mean knowledge score was $(14 \pm 2.46)$ and mean percentage was $56 \%$. 
International Journal of Trend in Scientific Research and Development (IJTSRD) ISSN: 2456-6470

Table No-2 Area wise knowledge of mothers regarding warning signs of pregnancy

$\mathbf{N}=\mathbf{5 0}$

\begin{tabular}{|c|c|c|c|c|}
\hline Area of knowledge & Total score & Range Score & Mean \pm SD & Mean Percentage \\
\hline $\begin{array}{l}\text { Introduction to warning } \\
\text { signs }\end{array}$ & 4 & $0-4$ & $2.26 \pm 0.94$ & $56.5 \%$ \\
\hline PV Bleeding & 3 & $0-3$ & $2 \pm 0.69$ & $50 \%$ \\
\hline Severe Vomiting & 5 & $0-5$ & $2.44 \pm 1.01$ & $61 \%$ \\
\hline Unusual Swelling & 3 & $0-3$ & $1.7 \pm 0.67$ & $42.5 \%$ \\
\hline $\begin{array}{ll}\text { Decreased fetal } \\
\text { movement }\end{array}$ & 5 & $1-5$ & $2.72 \pm 0.83$ & $68 \%$ \\
\hline Anemia & 3 & $0-3$ & $1.74 \pm 0.69$ & $43.5 \%$ \\
\hline Per vaginal discharge & 2 & $0-2$ & $1.14 \pm 0.40$ & $28.5 \%$ \\
\hline
\end{tabular}

Table no 2 shows the area wise knowledge score regarding warning signs of pregnancy the highest mean score and percentage was $(2.72 \pm 0.83),(68 \%)$ in the area of decreased fetal movement and the lowest was $(1.14 \pm 0.40),(28.5 \%)$ in the area of per vaginal discharge.

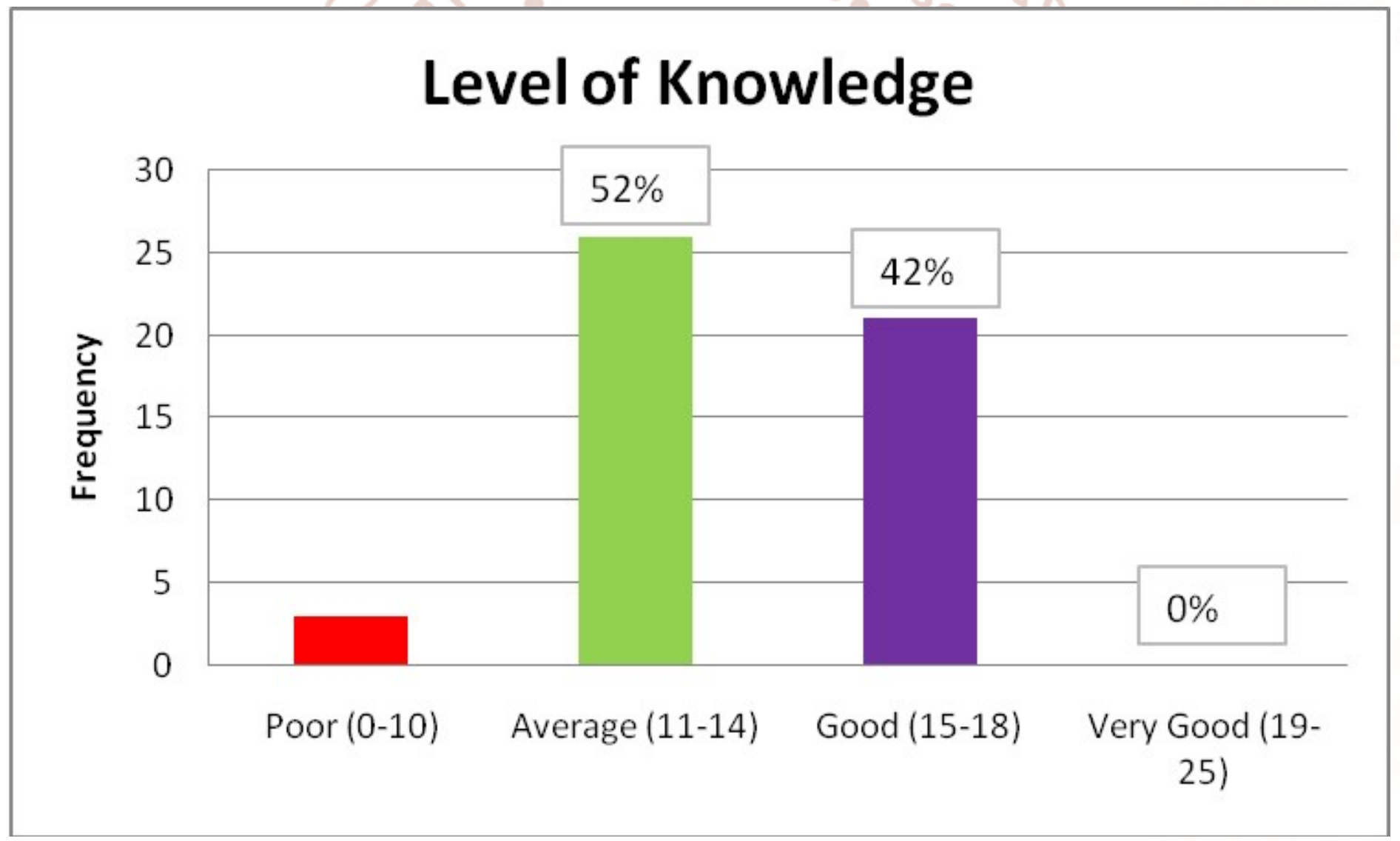

Figure no.1 Frequency and percentage of knowledge score according to arbitrary category

Figure 1 describes the frequency and percentage of knowledge score according to arbitrary category among antenatal mothers. Result shows that $6 \%$ mothers had poor level of knowledge (score 0-10) regarding warning signs of pregnancy, 52\% mothers had average level of knowledge (score 11-14) regarding warning signs of pregnancy, 42\% mothers had good level of knowledge (score 15-18) regarding warning signs of pregnancy and no one were in the category of good level of knowledge . 
Association between level of knowledge score with their selected demographic variables.

Table No-3 Association between level of knowledge score with their demographic variables.

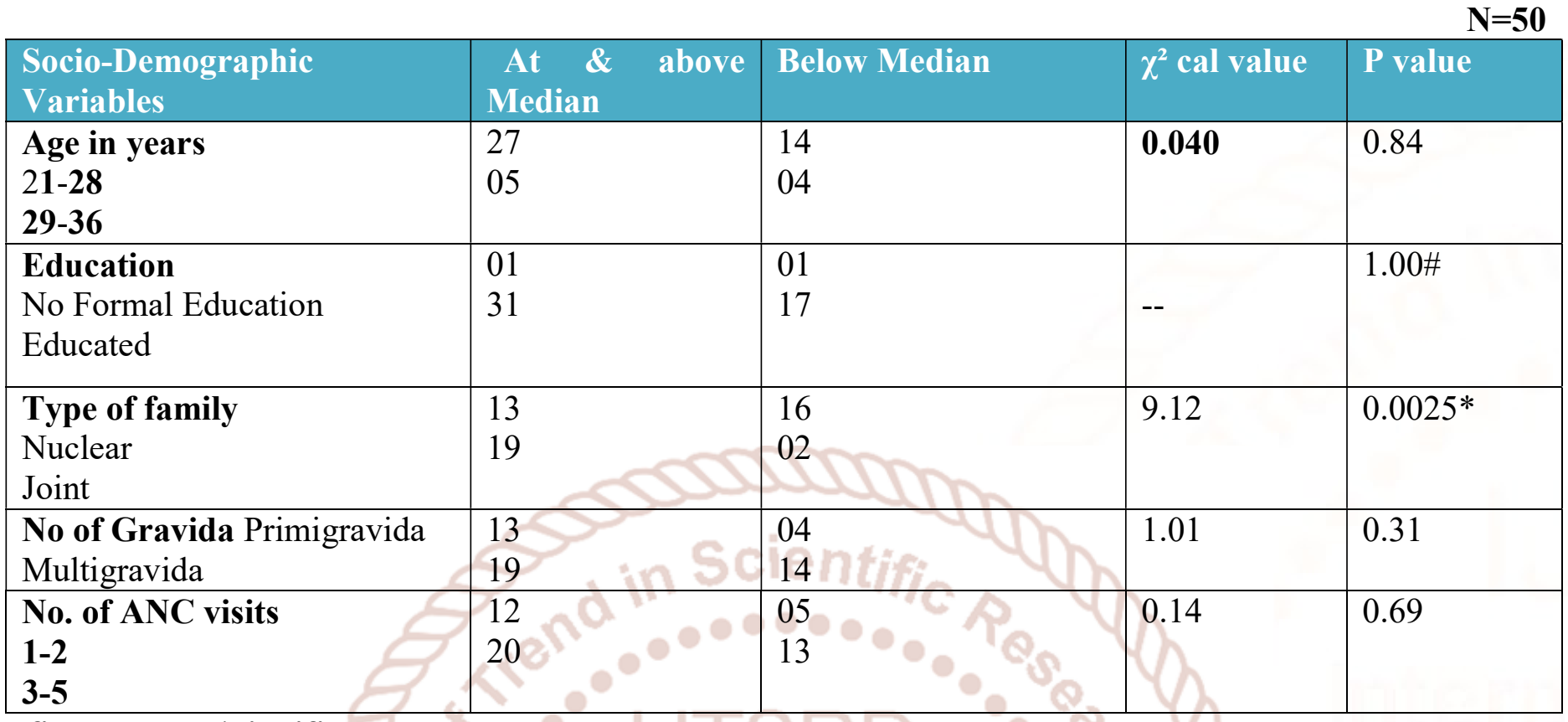

\section{\# fisher exact, *significant}

Table no.3 shows that only type of family had highly statistical significant association with the knowledge score at the level $\mathrm{p}<0.05$. Other Socio-Demographic variables like Age, Education, No. of Gravida, and Number of Antenatal Clinic visits statistically not having any association with knowledge score at the level $p<$ 0.05 .

\section{DISCUSSION}

A cross sectional study was conducted to assess the knowledge of antenatal mothers regarding warning signs of pregnancy. Knowledge of warning signs of pregnancy is a very essential step for appropriate and timely referral. The findings of this study has provided an insight information among pregnant women's knowledge about warning signs of pregnancy, which could help in designing appropriate interventions and as a base for further wide scale studies in other part of the country or state.

In present study more than half $52 \%$ of the antenatal mothers had average level of knowledge and $42 \%$ had good level of knowledge. Study conducted by Radhika K showed that 26\% mothers were having average level of knowledge and $10 \%$ mothers were having good level of knowledge.

\section{CONCLUSION}

Form the finding of the study it can be concluded that highest mean score was in the area of decreased fetal movement and lowest mean score in the area of per vaginal discharge. Result shows that most $52 \%$ of the mothers were having average level of knowledge and only $42 \%$ had good level of knowledge regarding warning signs of pregnancy. There was no statistical significant association between level of knowledge score with selected demographic variables such as age, education, no. of gravida, no. of ANC visits and only type of family was having highly statistical association with the knowledge score.

\section{REFERENCES}

1. Nebiyu Maseresha, Kifle Woldemichael and Lamessa Dube,knowledge of obstetric danger signs and associated factors among antenatal mothers, cited in 2016: Available form; https://bmcwomenshealth.biomedcentral.com/trac k/pdf/10.1186/s12905-016-0309-

3 ? site $=$ bmcwomenshealth.biomedcentral.com 
2. Mesay Hailu, Abebe Gebremariam, Fessahaye Alemseged, knowledge about obstetric danger signs among pregnant women, cited in 2015: Available

From; https://www.ncbi.nlm.nih.gov/pmc/articles/PMC3 275898/pdf/EJHS2001-0025.pdf

3. Denial Bogale and Desalegn Markos,knowledge of obstetric danger signs among child bearing women, cited in 2015, Available From; http://download.springer.com/static/pdf/790/art $\% 2$ 53A10.1186\%252Fs12884-015-0508-

1.pdf?originUrl $=\mathrm{http} \% 3 \mathrm{~A} \% 2 \mathrm{~F} \% 2 \mathrm{Fbmcpregnancy}$ childbirth.biomedcentral.com\%2Farticle\%2F10.1 186\%2Fs 12884-015-05081 \&token $2=\exp =1495698420 \sim$ acl $=\% 2$ Fstatic $\% 2 \mathrm{Fp}$ df\%2F $790 \% 2$ Fart $\% 25253 \mathrm{~A} 10.1186 \% 25252 \mathrm{Fs} 128$ 84-015-0508-

1.pdf* $\mathrm{hmac}=025 \mathrm{c} 0 \mathrm{ffd} 946 \mathrm{df} 5 \mathrm{~d} 31515974508 \mathrm{a} 8 \mathrm{f} 9$ cfca44ac1f8af1 fb36923af6fec82efc67

4. Renu Sangal, Reena Srivastav, Arvind K Singh, DK Srivastav, Meera, Huma Khan, knowledge regarding obstetric danger signs among women attending antenatal clinic, cited in 2014:ISSN0301-1216 Indian.J.Prev.Soc.Med.Vol.23. No 1.2012 Available http://medind.nic.in/ibl/t12/i1/iblt12i1p11.pdf

5. Tesfaye Assebe Yadeta, Fekede Asefa Kumsa, Awareness and Health Care Practice of Mothers' About Obstetric Danger Signs, cited in 2017, Available From: http://article.sciencepublishinggroup.com/pdf/10.1 1648.j.jfmhc.20170301.15.pdf

6. Radhika K, assess the knowledge of selected warning signs of pregnancy among antenatal mothers, cited in 2016, Available From; http://14.139.159.4:8080/jspui/bitstream/1234567 89/2225/1/Copy\%20of\%20CDNN0BG00007.pdf

7. Henry V. , Sally E. Findley, Giorgio Cometto, Godwin Y. Afenyadu, cited in 2015: Available From; https://www.ncbi.nlm.nih.gov/pubmed/23377725

8. Anaam Ebrahim El-Nagar1, Manal Hassan Ahmed2, Ghada Abd El-Salam Belal, Awareness_and_Health_Care_Practice_of_Mothe rs\%27_About_Obstetric_Danger_Signs, cted in 2017, Avaialble From: https://www.researchgate.net/publication/3164929 55_Awareness_and_Health_Care_Practice_of_Mo thers\%27_About_Obstetric_Danger_Signs_at_Har amaya_District_Eastern_Ethiopia.
9. Tara Kumari Acharya , Ambika Poudel, Knowledge Regarding Obstetric Danger Signs Among Antenatal Mothers. Cited in 2017: Available From; http://www.uphtr.com/issue_files/IJNRP_16_VO L3_NO2_Tara7.pdf

10. Pembe AB , Urassa DP , Carlstedt A, Lindmark G,Nyström L and Darj E, on awareness of danger signs of obstetric ,cited in 2017, Available from: https://www.ncbi.nlm.nih.gov/pmc/articles/PMC2 667432/ 